\title{
Right bundle branch block during transvenous ventricular pacing
}

\author{
William S. Abernathy, M.D. \\ Barry J. Crevey, M.D. \\ Ann Arbor, Mich.
}

Cardiac pacing through a transvenous catheter located in the right ventricle usually produces a pattern of left bundle branch block (LBBB). When right bundle branch block ( $R B B B)$ occurs during apparent right ventricular pacing, a complication (perforation or malposition of the catheter) has usually occurred. In the patient reported here, uncomplicated right ventricular transvenous pacing produced RBBB. Recognition of this uncommon event is important because it may save the patient the risk and inconvenience of repositioning a properly functioning pacing catheter.

\section{Case report}

R. T., an 84-year-old man, was admitted to the hospital with a seven-month history of syncope, angina pectoris, and congestive heart failure. Physical examination showed a grade $3 / 6$ aortic systolic ejection murmur and an absent aortic component of the second heart sound. The carotid pulse upstroke was markedly delayed by palpation. Roentgenograms of the chest and cardiac fluoroscopy revealed marked calcification of the aortic valve and mild enlargement of the left ventricle.

The initial electrocardiogram (Fig. 1) showed sinus rhythm, complete atrioventricular block, and an idioventricular rhythm. Pacing through a transvenous bipolar electrode catheter produced RBBB. An electrogram recorded from the distal electrode demonstrated a dominant S-wave characteristic of recordings from the apex of the right ventricle (Fig. 2). ${ }^{1}$ For the seven days this catheter was in place the stimulating threshold was always less than $1.0 \mathrm{ma}$. No pericardial rub was heard, and no complications developed.

Pacing through a permanent transvenous catheter (Med tronic No. 5818) again produced RBBB. The stimulating threshold was 1.4 ma. No complications developed in the

From the Section of Cardiology (Heart Station), Department of Internal Medicine, The University of Michigan Medical Center, Ann Arbor, Mich. 48104.

Received for publication Jan. 14, 1974.

Reprint requests: W. S. Abernathy, M.D., 1875 Lake Lila Dr., Ann Arbor, Mich. 48105. hospital, and re-examination $2^{1 / 2}$ months later revealed no complications and no change in the electrocardiogram.

Fig. 3 shows the position of the catheters.

\section{Discussion}

That these catheters were in the right ventricle is demonstrated by their position on the roent. genograms, by the appearance of the electrogram, by the constant and low stimulating threshold, by the constantly normal pacing and sensing functions, and by the absence of complications. Any one of these factors alone is inadequate to insure the site of the cather tip, ${ }^{1}$ but taken together they argue strongly for the right ventricular location of the tip.

Transvenous pacing may produce $\mathrm{RBBB}$ if the catheter tip perforates the myocardium or ventricular septum..$^{2-4}$ Stimulation from the coronary sinus often gives a RBBB configuration., i, 5 These are probably the most common causes of RBBB during transvenous pacing.

There are twelve reported cases in which RBBB occurred during uncomplicated transvenous pacing..$^{5-8}$ In only seven cases was long-term stable pacing maintained with this pattern, and in five of those cases, the RBBB pattern was intermittent. Bauman, Lamb, and Tsagaris ${ }^{6}$ have noted two forms of RBBB in this context. They described one case of classic RBBB $\left(R V_{1}, S_{1}\right)$ and five cases of atypical and intermittent RBBB $\left(R V_{1}\right.$, without $\left.S_{1}\right)$. Of the twelve cases of $R B B B$ during transvenous pacing, five were of the classic type and seven were atypical.

In the case reported here, pacing through the temporary catheter produced the classic RBBB pattern (Fig. 2), while pacing through the permanent catheter produced the atypical RBBB configuration (not shown). This case is noteworthy because stimulation from two sites within the 


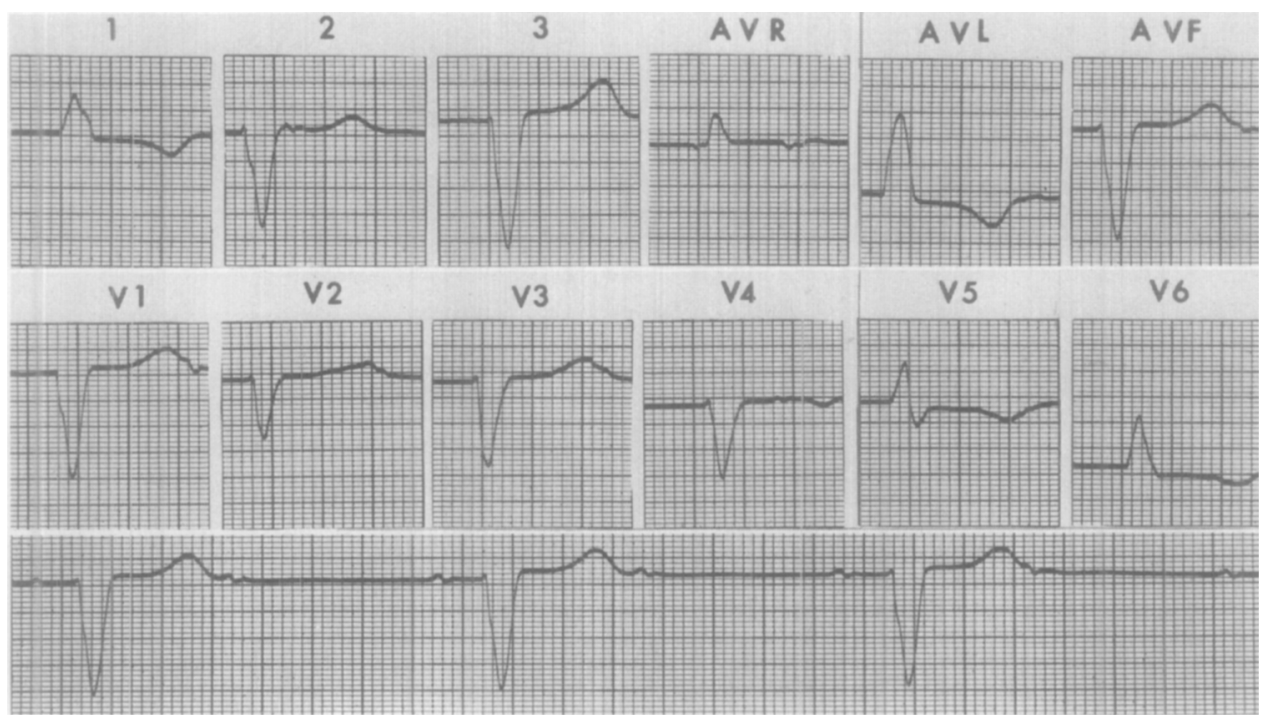

Fig. 1. Electrocardiogram and rhythm strip recorded at $50 \mathrm{~mm}$. per second. All leads are full standard $(1 \mathrm{mv} .=10$ $\mathrm{mm}$.) except Leads $V_{3}$ and $V_{4}$ which are one-half standard. See Text.

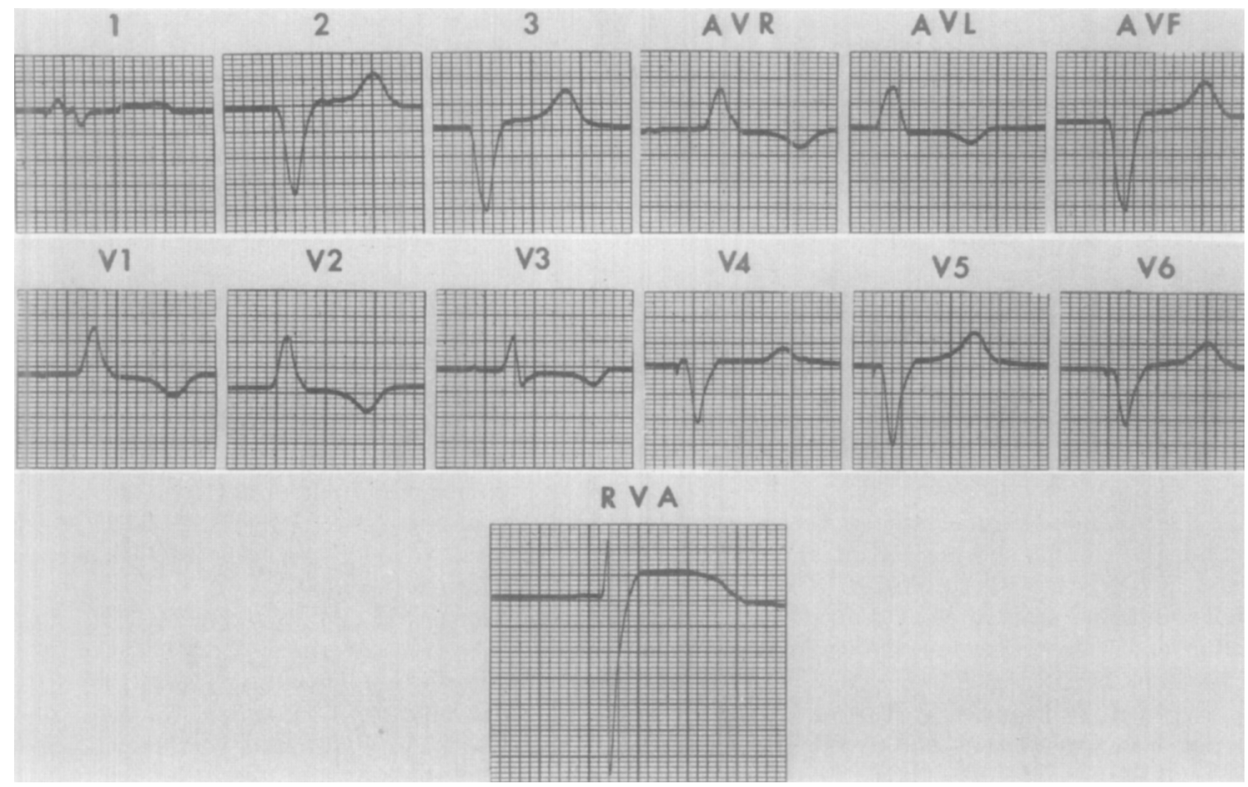

Fig. 2. Electrocardiogram and electrogram recorded from the apex of the right ventricle (RVA) at $50 \mathrm{~mm}$. per second. All leads are one-half standard $(1 \mathrm{mv} .=5 \mathrm{~mm}$.) except Iead I which is full standard and Lead RVA which is one-fifth standard. See text.

right ventricle gave a $R B B B$, because the $R B B B$ was persistent, and because long-term stable pacing was achieved with this pattern.

It is not known why right ventricular pacing sometimes leads to RBBB. Preferential activation of the left bundle branch may occur through stimulation of ramifications of the left bundle branch which extend to the right side of the ventricular septum. Delayed conduction in the right bundle branch may lead to RBBB during transvenous pacing. ${ }^{5-7}$

When RBBB is found during transvenous ventricular pacing, a complication (perforation or malposition) has probably occurred. However, this electrocardiographic pattern is compatible with uncomplicated pacing, and repositioning the catheter may not be necessary. The location of the catheter tip should be verified by viewing 


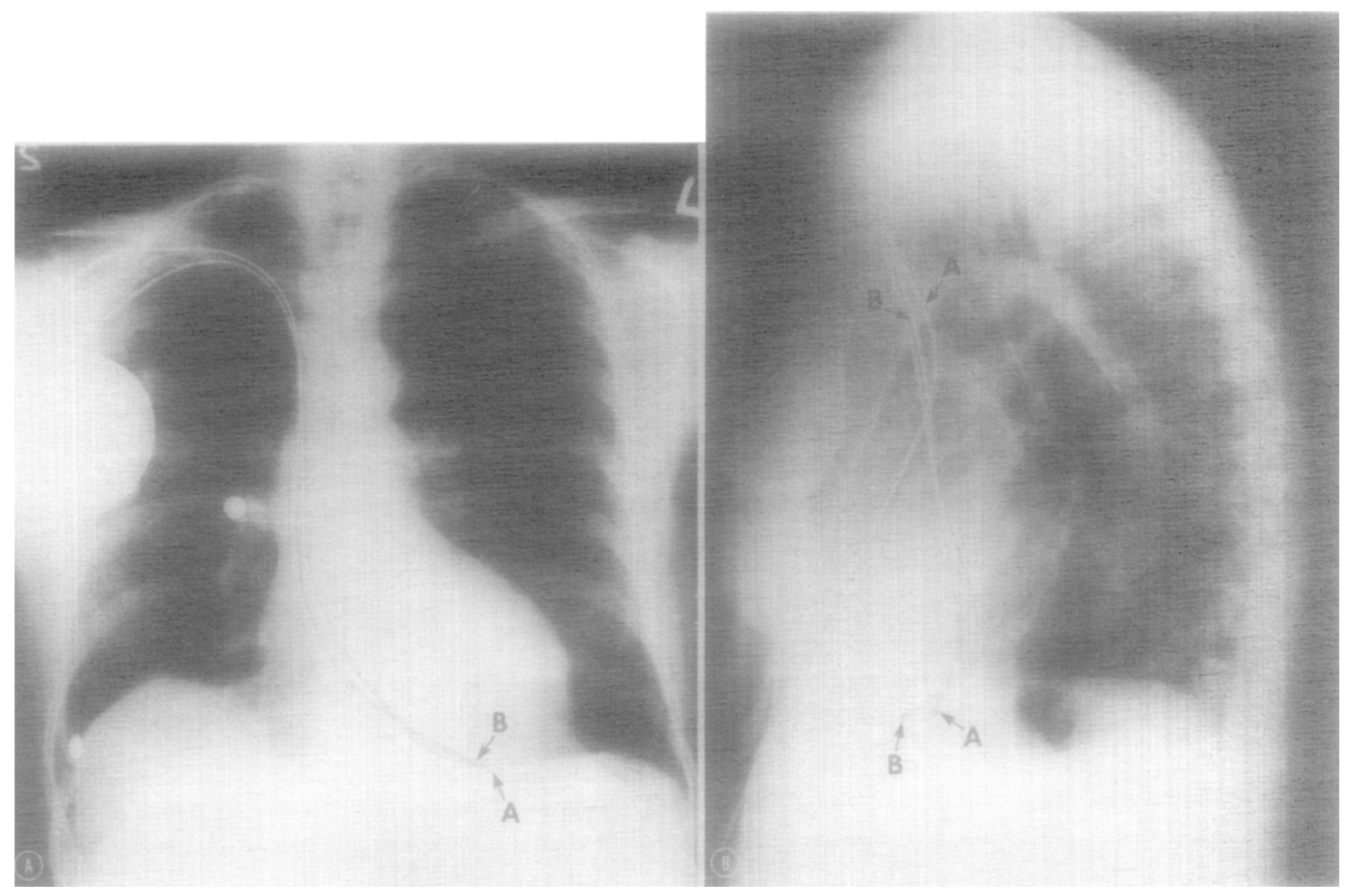

Fig. 3. Frontal and lateral roentgenograms of the chest showing the temporary $(A)$ and permanent $(B)$ pacing catheters (retouched for clarity). See text.

roentgenograms, by recording an electrogram from the distal electrode, and by measuring the stimulating threshold.

\section{REFERENCES}

1. Gulotta, S. J.: Transvenous cardiac pacing. Technics for optimal electrode positioning and prevention of coronary sinus placement, Circulation 42:701, 1970.

2. Stillman, M. T., and Richards, A. M.: Perforation of the interventricular septum by transvenous pacemaker catheter, Am. J. Cardiol. 24:269, 1969.

3. Torresani, J., Bernard, Y., Monties, J. R., and Jouve, A.: Clinical experience in transvenous and myocardial pacing, Ann. N. Y. Acad. Sci. 167:995, 1969.
4. Castellanos, A., Maytin, O., Lemberg, L., and Castillo, C.: Unusual QRS complexes produced by pacemaker stimuli, Am. Heart J. 77:732, 1969.

5. Barold, S. S., Narula, O. S., Javier, R. P., Linhart, J. W., Lister, J. W., and Samet, P.: Significance of right bundlebranch block patterns during pervenous ventricular pacing, Br. Heart J. $31: 285,1969$.

6. Bauman, D. J., Lamb, K. C., and Tsagaris, T. J.: Unusual QRS wave forms associated with permanent pacemakers, Chest 64:480, 1973.

7. Mower, M. M., Aranaga, C. E., and Tabatznik, B.: Unusual patterns of conduction produced by pacemaker stimuli, AM. HeArT J. 74:24, 1967.

8. Castellanos, A., Lemberg, L., Salhanick, L., and Berkovits, B. V.: Pacemaker vectorcardiography, AM. HEART J. 75:6, 1968. 